\title{
Exposing the patterns of statistical blindness: Centring indigenous standpoints on student identity, motivation, and future aspirations
}

Australian Journal of Education $0(0) \mathrm{I}-25$

(C) Australian Council for Educational Research 2017

Reprints and permissions: sagepub.co.uk/journalsPermissions.nav DOI: 10.1 |77/0004944|I773।360 journals.sagepub.com/home/aed

@SAGE

\section{Gawaian Bodkin-Andrews and}

\section{Alison Whittaker}

Centre for the Advancement of Indigenous Knowledges, University of

Technology Sydney, Australia

\section{Neil Harrison}

Department of Educational Studies, Macquarie University, Australia

\section{Rhonda Craven and Philip Parker}

Institute for Positive Psychology and Education, Australian Centre for Indigenous Thriving, Australian Catholic University, Australia

\section{Michelle Trudgett and Susan Page}

Centre for the Advancement of Indigenous Knowledges, University of Technology Sydney, Australia

\section{[AQ1]}

\begin{abstract}
This article engages with an Indigenous Quantitative Methodological Framework to examine links between a positive sense of cultural identity, future aspirations, and academic motivational tendencies. Utilising a sample of Aboriginal, non-Aboriginal and First Generation (Migrant) Australian students in years 7-10, results showed strong psychometric properties across the three groups for the measures utilised. Whilst few differences were identified between the First Generation and non-Aboriginal Australian students, Aboriginal students consistently had lower future aspirations and less adaptive motivational tendencies than the two other student groups. Importantly though, Aboriginal students held a stronger sense of cultural identity. Key links between
\end{abstract}

\section{Corresponding author:}

Gawaian Bodkin-Andrews, University of Technology, Broadway, PO Box 123, Sydney, New South Wales 2007, Australia. Email: gawaian.bodkin-andrews@uts.edu.au 
motivation and cultural identity were identified, and both were associated with stronger educational and life aspirations. The implications suggest that researchers and teachers need to recognise the importance of cultural identity as a positive driver for schooling motivation and future aspirations, and that First Nations theory and research should be engaged to override the erasing effects of Western epistemological standpoints when utilising statistical methods.

\section{Keywords}

Aboriginal students, First Nations, school education, motivation, cultural identity, aspirations, indigenous quantitative methods, statistical methods

Cross-cultural advances in academic motivation and engagement literature have captured substantial attention across international research and teaching practices (Martin, Yu, Papworth, Ginns, \& Collie, 2014; McInerney \& King, 2013). Whilst this research has established the 'psychometric validity' of varying motivation measures for a diversity of cultural and ethnic groups, this article takes a more critical standpoint by examining links (or lack thereof) between statistical validity and the cultural responsiveness of statistical research (Smith, 2012). Predominately, motivational research has been largely focussed on an epistemological centring of Western frameworks (e.g., McInerney \& King, 2013; Magson, Bodkin-Andrews, Craven, Nelson, \& Yeung, 2013; Martin, Ginns, Papworth, \& Nejad, 2013). Although identifying and understanding practices that strongly engage students is of critical importance, research and teaching initiatives should also ensure that practices that are culturally reinforcing for students from varying social and cultural backgrounds, particularly for First Nations students are prioritised (Bodkin-Andrews \& Carlson, 2016; Preston \& Claypool, 2013; Walter \& Butler, 2013). Motivational researchers should consider moving beyond Western-only frameworks, as there is a long history of educational research that has ignored, alienated, demonised, and oppressed the strengths of students' cultures within the schooling system, especially within First Nations and Indigenous contexts (Nakata, 2007; Smith, 2012).

The analyses within this article apply the theoretical lens of Indigenous scholars who are working within Indigenous Standpoint Theories and emerging Indigenous Quantitative Methodological Frameworks (e.g., Andersen, 2016; Kukutai \& Walter, 2015; Lovett, 2016; Walter \& Andersen, 2013). As a result, the literature reviewed and results discussed are centred on research standpoints that embrace Australia's First Peoples (Aboriginal Australians), and a critical lens is cast over the measures and results for their relevancy towards existing Aboriginal Australian and international First Nations-led research.

\section{Statistics and Aboriginal and Torres Strait Islander peoples}

It is critical to note that there is an established history of Aboriginal and Torres Strait Islander peoples', communities', and scholars' mistrust of positivistic Western research methodologies. Quantitative methods are frequently viewed as the archetype of Eurocentrism and deficit reasoning (Nakata, 2007; Walter, 2010). Walter (2010) highlights the fallacy behind notions of neutrality and objectivity in quantitative research, and points to numerous biases that undermine approaches to and interpretations of quantitative data that 'represent' Aboriginal and Torres Strait Islander peoples. Examples include pejorative 
evidence where data and results are mispresented to rationalise and justify ideological and epistemological bias. Walter also identifies simplistic interpretations that are realised through the undemanding critique of existing data, often characterised by findings of 'progress' or 'disaster' that fail to capture the greater complexities behind the research questions being investigated. Finally, Walter lists the critical concern of the dichotomous orthodoxy of Indigeneity that repeatedly manifests itself in quantitative research (i.e., 'Aboriginal vs. non-Aboriginal'). Not only does such a dichotomous variable fail to adequately represent the vast diversity of Aboriginal and Torres Strait Islander nations, language groups, and contexts (or non-Indigenous groups for that matter), but when combined with pejorative and simplistic biases, only serve to further frame Indigeneity within a dominant Western epistemology that has systemically silenced diverse Aboriginal and Torres Strait Islander epistemologies, axiologies, and ontologies (Martin, 2008; Moreton-Robinson \& Walter, 2009).

Intriguingly, Walter (2010) points out that there are alternatives to Eurocentric quantitative methodologies and proposes that statistics may be engaged using an Indigenous research methodological framework. That is:

...in contrast to silent, presumptive objectivity, Indigenous quantitative methodology places race at the centre of its approach. Indigenous voices and knowledges are explicitly foregrounded ... Indigenous statistics can portray a unique, compelling picture of contemporary Indigenous peoples within this society of value and validity in their own right. (p. 53)

Whilst there is an emerging research base that is more strongly linking Indigenous epistemologies with statistical methods (cf. Kukutai \& Taylor, 2016; Walter, Martin, \& BodkinAndrews, 2017), there are many existing statistical databases of both primary and secondary data that have actively silenced Indigenous standpoints in research. This raises the question as to whether such pre-existing research can still be engaged with (and possibly corrected) from a critical Indigenous standpoint? This article revisits data originally collected for the primary author's PhD studies, completed in 2008. Whilst this author is Aboriginal Australian (of the D'harawal language group), his increasing engagement with Indigenous Research Methodologies (Kovach, 2009; Martin, 2008) has allowed him to critically self-identify the bi-epistemic pressures on First Nations scholars situated within primarily non-Indigenous research institutions (Muller, 2014; Shay \& Wickes, 2017). Rather than completely dismissing his previous works and methods based-learnings, he re-engages the data from an Indigenous Quantitative Methodological Framework (Walter \& Anderson, 2013).

\section{Multiple dimensions of academic motivation - The Western context}

International research has shown varied links between numerous motivational factors and increased schooling aspirations, engagement and achievement (Covington, 2000; Martin, 2009; Urdan \& Maehr, 1995). Such research has revealed the importance of capturing the complex reality of multidimensional emotions, cognitions and behaviours that may underlie the motivation of any individual student. Capitalising upon this need, Martin (2009) established the 11-factor Motivation and Engagement Scale (MES). The MES was formulated to capture a 'student's energy and drive to learn, work effectively and achieve their potential at school and the behaviours that follow from this energy and drive' (Martin, 2009, p. 88). 
The first three factors: mastery, value of school and self-belief of the MES fall under a broad adaptive cognitive framework that emerged from the foundations of self-efficacy, expectancy-value, and self-worth theories (Bandura, 1997; Covington, 2000; Nicholls, 1989). The MES captures another three adaptive behavioural factors (persistence, planning, study management) that not only drew from Bandura and Covington's works, but also behavioural change models (Beck, 1996), and learning strategy models (Pintrich \& Garcia, 1991). A third motivational domain focussed on impeding cognitions (uncertain control, failure avoidance, and anxiety) that captured elements of attribution, achievement and self-worth theories (Covington, 2000). Finally, Martin (2009) identified two maladaptive behavioural dimensions (disengagement and self-handicapping) that drew from research identifying where students may explicitly or implicitly dissociate from the learning processes (Abramson, Seligman, \& Teasdale, 1978).

\section{Measuring motivation across cultures?}

One of the strongest features of the MES is that it has been found to be a psychometrically sound measurement instrument across primary, secondary, and university educational levels, and has shown significant associations with a range of schooling outcomes, including measures of school enjoyment, classroom participation, academic buoyancy, positive educational intentions and homework completion (Liem \& Martin, 2011; Martin et al., 2014). Further research has suggested that the MES has statistical utility across age and gender, as well as across student groups from a number of cultures, including the United Kingdom, North America, China and Australia (Martin et al., 2014).

\section{Aboriginal and Torres Strait Islander student schooling outcomes and motivation}

A recent government report on the life standards of Aboriginal and Torres Islander peoples (Steering Committee for the Review of Government Service Provision (SCRGSP), 2014) found that there is still a substantial gap between the educational outcomes of Aboriginal and Torres Strait Islander children and their non-Indigenous Australian counterparts. For example, with regard to completing the final year of high school (Year 12), it was found that only 58.5\% of Aboriginal and Torres Strait Islander 20-24 year olds had completed Year 12 when compared to $86.1 \%$ of non-Indigenous young adults. This finding is further exacerbated when considering that, of the Aboriginal and Torres Strait Islander students who did complete Year 12, only $7.3 \%$ were given a university entrance rank (Australian Tertiary Admission Rank (ATAR)) score greater than 50 (a minimum prerequisite for some university courses) when compared to $44.3 \%$ of the non-Indigenous population. These results highlight the lack of equity between all levels of educational outcomes for Aboriginal and Torres Strait Islander and non-Indigenous Australian students (De Bortoli \& Thompson, 2010).

Numerous authors have raised the need to identify links between patterns of achievement and motivation for Indigenous students within education (De Bortoli \& Thompson, 2010; Martin, 2006). Importantly, links between a diversity of motivational constructs and varying schooling outcomes have been identified for Aboriginal and Torres Strait Islander students, with results revealing significant associations with school engagement and enjoyment, future aspirations, and absenteeism (Bodkin-Andrews, Craven, Parker, Kaur, \& Yeung, 2013; McInerney \& King, 2013; Martin et al., 2013; Mooney, Seaton, Kaur, Marsh, \& 
Yeung, 2016). Whilst some of this research suggests that Aboriginal and non-Aboriginal student links between motivation and schooling outcomes may show more similarities than differences (McInerney \& King, 2013; Mooney et al., 2016), Bodkin-Andrews, Craven, Parker, Kaur, and Yeung (2013) warn that there is a general tendency for motivational factors to have weaker associations with educational outcomes for Aboriginal students when compared to their non-Indigenous counterparts. They move on to argue that research has largely failed to identify unique cultural factors drawn from Aboriginal epistemologies that may contribute to stronger links between motivation and schooling outcomes.

\section{Academic motivation and identity}

There is a notable silence across nearly all of the quantitative motivational research focussing on Aboriginal and Torres Strait Islander students concerning the inclusion of cultural identity and pride. This may be argued to be a continuation of the trend of research practices failing to consider the diverse lived experiences and knowledges of Aboriginal and Torres Strait Islander peoples (Moreton-Robinson \& Walter, 2009). Some have suggested that the overemphasis on Western frameworks has further alienated Aboriginal students from the intrinsic benefits of linking culture with schooling pursuits, thus potentially perpetuating the long-standing educational inequities still evident today (BodkinAndrews \& Carlson, 2016; Kickett-Tucker, 2009; Walter \& Butler, 2013).

Some existing qualitative evidence supports links between cultural identity and academic motivation. Munns, Martin, and Craven (2008) conducted a study of Aboriginal primary school students, and found that although highly motivated, Aboriginal students were aware of low expectations placed upon most Aboriginal students within their schools, and yet they had a strong sense of pride in who they were as Aboriginal Australians. As a result, Munns and colleagues suggested that teachers should be aware of more complex understandings of students' sense of identity within the classroom (see also Munns, O'Rourke, \& BodkinAndrews, 2013). In teacher interviews, Harrison and Greenfield (2011) found a strong link between lowered suspension levels and the incorporation of specific and localised Aboriginal Knowledges within the curriculum. This suggests that stronger engagement with localised Aboriginal knowledges may be an important source of pride for Aboriginal students. Finally, within the international context, Preston and Claypool (2013) found that Canadian Aboriginal school students voiced strong themes promoting a trusting school environment and culture, flexible learning possibilities, family and cultural role models, and sensitivity and awareness of student and cultural histories as key elements behind increasing their sense of academic motivation, as well as linking academic motivation to their already strong sense of Aboriginal identity.

In contrast to the above findings, some researchers and commentators have questioned the value of respecting or promoting Aboriginal culture and identity within the schooling environment. Such opposition suggests that cultural learnings are oppositional to dominant educational standards, that such learnings are simply a waste of time, and even that they may even be maladaptive for schooling outcomes (Hughes \& Hughes, 2012; Pearson, 2011). For example, Hughes and Hughes (2012, p. 1) argued that:

More than $\$ 360$ million is being spent on Indigenous-specific 'culturally appropriate' literacy and numeracy programs each year. These programs are not only wasteful but actually counterproductive because they take attention and resources away from classroom instruction. 
Such dialogues are not limited to non-Indigenous commentators, as Noel Pearson (2011) has repeatedly critiqued the value of strengthening Aboriginal identities within educational contexts (see Moreton-Robinson, 2009 and Smallwood, 2015 for strong critiques of Pearson's position). More specifically, Pearson (2011) suggested an emphasis on 'individual character' and likened the strengthening of 'racial' or 'ethic' identities to a form of chauvinism. In short, Pearson argued that that being 'strong and smart ... ends up selling Indigenous students an illusion. Racial Identity, no matter how confidently held, can't guarantee success' (p. 115).

Limitations from such 'research' questioning the value of Aboriginal and Torres Strait Islander identities within classrooms may be typified by an over-emphasis on broad population data (e.g., policy funding and population statistics), Western ideological underpinnings, simplistic interpretations that fail to capture the complexities of diverse school and individual level data sources, and the targeting of 'Indigenous' programmes as the sole negative explanatory variable for outcomes (e.g., standardised achievement) that are not critiqued for their Eurocentric foundations (Ford, 2013; Walter, 2010).

With the contrasts between qualitative and quantitative findings on the links between Aboriginal identity and positive schooling outcomes, there is a need for researchers to more carefully examine the statistical evidence of the role of culture and identity in further engaging with the educational experiences of Aboriginal and Torres Strait Islander students. As a result, this article aims to:

a. Examine the psychometric validity of a measure of Cultural Identity and the MES within Confirmatory Factor Analysis (CFA) testing frameworks;

b. Determine if there are any significant differences in the mean scores for Cultural Identity, Motivational factors, and Future Aspirations for Aboriginal, non-Aboriginal, and First Generation Australian students;

c. Identify the extent to which, after controlling for background variables, Cultural Identity may predict diverse Motivational tendencies and Future Aspirations for each student group; and

d. Determine if varying Motivational factors may still be associated with future aspirations after controlling for the predictive power of background variables and sense of cultural identity.

\section{Methods}

\section{Participants and procedure}

A total of 1,805 secondary school students (Years 7 to 10) were recruited across five government-funded public schools within the Australian state of New South Wales (NSW). These schools were located in one metropolitan, two urban, and two rural settings. The student sample consisted of 387 Aboriginal Australian students (179 males, 208 females), 1,056 non-Aboriginal Australian (560 males, 496 females) students, and 363 First Generation Australian students (192 males, 170 females). The First Generation Australian students were identified by either themselves or one of their parents as being born overseas. This broad grouping was utilised because more accurate and appropriate measures of ethnicity (e.g., specific cultural groups or English second language groups) did not produce a sample size adequate for the analyses within this investigation. Ages of the 
students ranged from 11 to 17 years, with a mean age of 13.48 years for the Aboriginal students, 13.70 years for the First Generation students, and 13.62 years for the nonAboriginal students.

Under the guidance of the NSW Aboriginal Education Consultative Group and the then NSW Department of Education and Training, the selection of participating schools emphasised a significant but minority population (10-40\%) of Aboriginal Australian students. These schools were selected to ensure that the sample of Aboriginal Australian students was large enough for the proposed statistical analyses.

The required ethical clearance was obtained prior to the commencement of the study. Data were gathered only from students or parents/primary carers who provided informed consent with information and consent forms having previously been provided to principals, parents/primary carers and students, and any participant being allowed to withdraw from the study at any stage. All surveys were completed in school year groups, in school halls and under exam conditions. It is important to note that the data within this investigation were originally part of a PhD project finalised in 2008. Whilst the data related to the motivation instrument have been previously published (Bodkin-Andrews et al., 2013), the identity measure has yet to be related to the motivation and/or goal aspirations measures.

\section{Measures}

MES - High school (Martin, 2009). This is an 11-factor, 44-item scale - four items per factordesigned to measure six adaptive dimensions, three impeding dimensions and two maladaptive dimensions of motivation. Students responded to the motivational items on a Likert Scale ranging from '1' ('Strongly Disagree') to '7' ('Strongly Agree').

Cultural identity (Drawn from Cameron, 2004). This was measured using six positively worded items drawn from the larger Social Identification Scale, which included positively worded questions concerning cultural ties, centrality and affect. All items were measured on a 6point Likert Scale, with higher values indicating greater levels of agreement to having a positive sense of cultural identity.

Confidence in future aspirations. Three single item measures were utilised to assess how confident the students were with regard to their aspirations for achieving their future goals regarding family, job, contribution to society and were answered on a 6-point Likert scale (' 1 ' = 'Strongly Disagree' to ' $6=$ Strongly Agree').

School aspiration. This was measured using a single item designed to capture when students would aspire to leave school. Response options ranged from 'as soon as I can' (1), 'before I finish Year 12' (2), and 'After I finish the last year of school' (3).

University aspiration. This was measured using a single item where students were able to select whether they would want to go to university after they leave school (coded as $-1=$ No, $1=$ Yes).

Background variables. Several background variables were included in this investigation, including gender (-1 Male, 1 Female), Grade (7, 8, 9, to 10), whether at least one parent/caregiver had attended university $(-1=$ no, $1=$ yes $)$, whether at least one parent 
had a full time job $(-1=$ no, $1=$ yes), and Home Educational Resources (HER; adapted from Craven et al., 2005) with a maximum score of 10 if a student indicated that all items on the list (e.g., a room of one's own, a desk to study on) could be found within the home environment.

\section{Statistical analysis}

Utilising the latent variable modelling programme MPLUS 7.31 (Muthén \& Muthén, 2012), a mixture of CFA and Structural Equation Modelling (SEM) techniques (Byrne, 2012) were employed. Firstly, with regard to examining the psychometric properties (Aim a), the initial analysis consisted of an unrestrained multi-group (Aboriginal Australian, non-Aboriginal Australian, First Generation Australian) CFA for the motivation and identity factors. Based on the methodology set out in Marsh, Tracey, and Craven (2006) the model's $a$ priori factor structure for each group (see Figure 1) was assessed using the goodness of fit indices of the Root-Mean-Square Error of Approximation ('RMSEA'), Comparative Fit Index ('CFI') and Tucker-Lewis Index ('TLI'). For the RMSEA, values less than .05 indicate reflect close fit (.08 acceptable), and values above .95 for the CFI and non-normed fit index (NNFI) represent excellent fits (.90 acceptable). The multi-group CFA was then extended into a series of factorial invariance tests where equivalence restraints were placed on the factor loadings (metric), item intercepts (scalar), factor covariances, and then item residuals of the motivation and cultural identity measures (Parker, Martin, Martinez, Marsh, \& Jackson, 2010). Variation of less than or equal to .01 of the CFI, and overlap in the $90 \%$ confidence interval of the RMSEA indicated that the assumptions of equivalence/invariance were met.

The second aim (Aim b) of identifying any significant mean differences across the latent factors and outcomes was achieved through three sets of analyses where dichotomous dummy variables were created to represent group comparisons (Aboriginal and nonAboriginal, Aboriginal and First Generation, non-Aboriginal and First Generation) and then regressed onto the motivation, cultural identity and future aspiration variables (Muthén \& Muthén, 2012).

Finally, a multi-group partial SEM with the factor loadings held invariant (Byrne, 2012) was conducted to address Aims (c) and (d). For Aim (c), standardised paths emanating from the background variables (e.g., gender, HER) and the latent cultural identity factor were regressed into the motivation and future aspirations measures. For Aim (d), the standardised residual correlations between the latent motivational factors and post-schooling outcomes were examined (effectively acting as a partial correlation where the predictive variance of the background variables and cultural identity are controlled). See Figure 2 for a summary representation of the structural model for aims (c) and (d).

\section{Results}

\section{Aim (a) psychometric properties and factorial invariance testing}

Table 1 offers the goodness of fit criteria for the multi-group CFA model, and suggests that the TLI, CFI, and RMSEA fit estimates are acceptable. All factor loadings are significant and moderate to strong in magnitude for each group ranging from .51 to .85 for the Aboriginal students, from .44 to .88 for the non-Aboriginal students, and from .46 to .90 


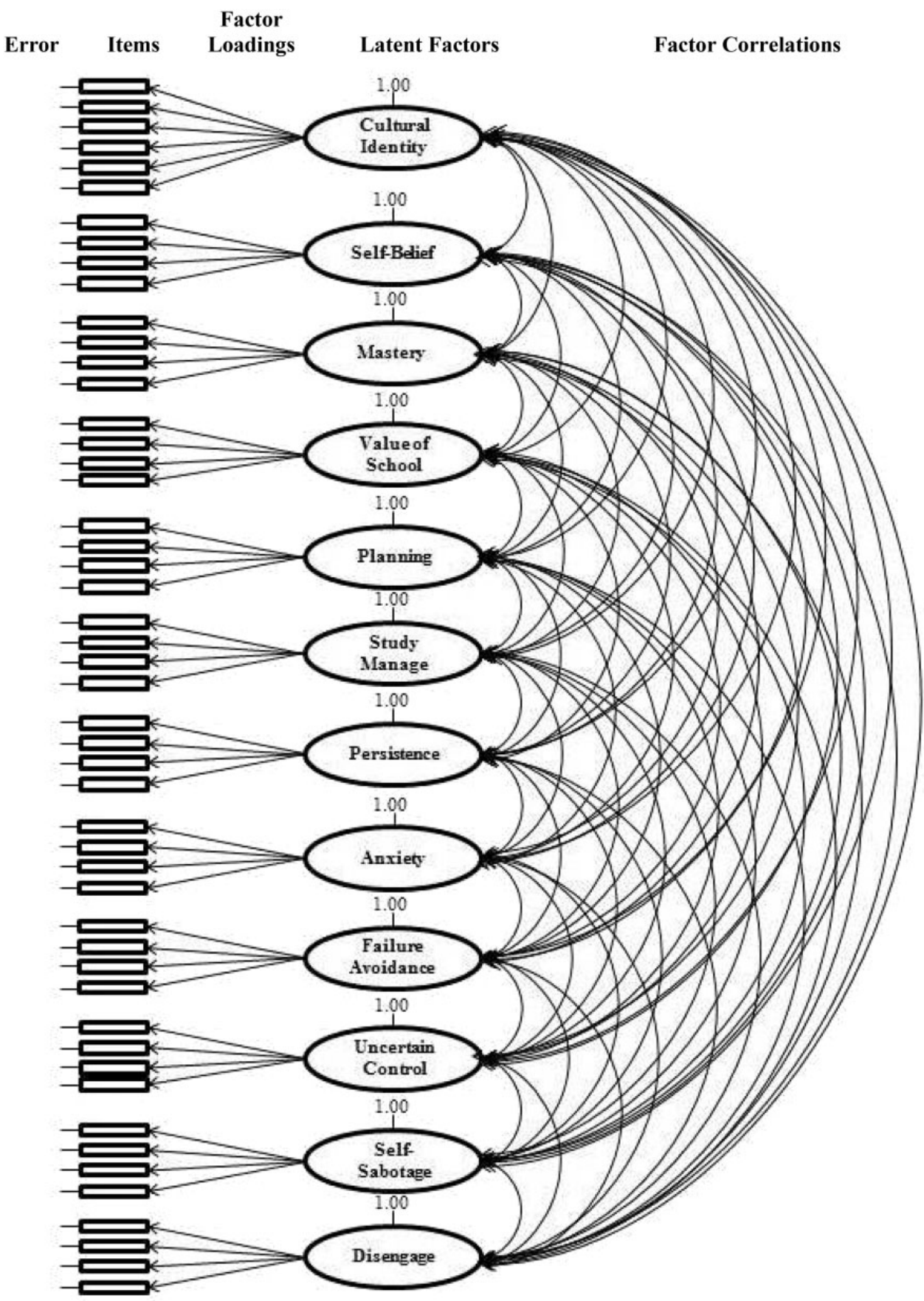

Figure I. CFA model of Motivation and Cultural Identity measures.

CFA: confirmatory factor analysis. 


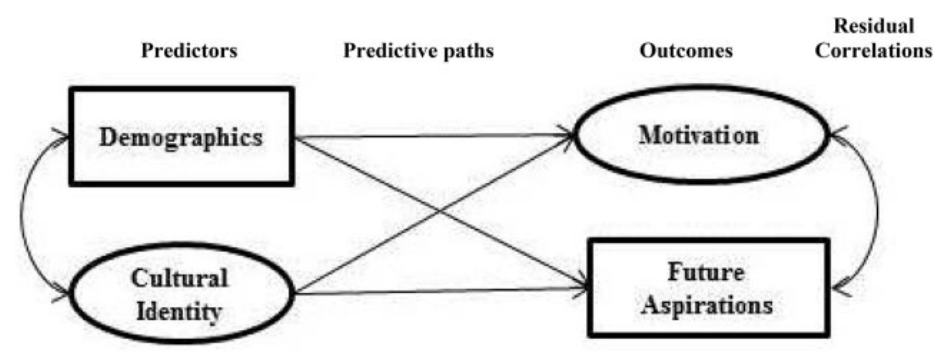

Figure 2. Summarised diagram for the Partial Structural Equation Modelling.

Table I . MES-HS and Cultural Identity multi-group (Aboriginal, non-Aboriginal, and First Generation Australian goodness of fit indices).

\begin{tabular}{|c|c|c|c|c|}
\hline$\chi^{2}$ & $d f$ & TLI & $\mathrm{CFI}$ & RMSEA \\
\hline 7168.75 & 3327 & .90 & .91 & .04 \\
\hline
\end{tabular}

Table 2 . MES-HS and cultural identity multi-group (Aboriginal, non-Aboriginal, and First Generation Australian) invariance testing.

\begin{tabular}{lllllll}
\hline \multicolumn{7}{c}{ Multi-group invariance testing } \\
\cline { 2 - 7 } & $\chi^{2}$ & $d f$ & TLI & CFI & RMSEA & 90\% RMSEA \\
\hline Model I: Completely free & $7,168.75$ & 3,327 & .902 & .911 & .044 & $.043-.045$ \\
Model 2: Factor loadings (FL) & $7,273.17$ & 3,427 & .905 & .911 & .043 & $.042-.045$ \\
Model 3: FL + item intercepts & $7,619.53$ & 3,527 & .901 & .905 & .044 & $.043-.045$ \\
Model 4: FL + factor correlations & $7,829.06$ & 3,659 & .903 & .904 & .044 & $.042-.045$ \\
Model 5: Completely fixed (all + residuals) & $8,538.74$ & 3,759 & .892 & .889 & .046 & $.045-.047$ \\
\hline
\end{tabular}

$\chi^{2}$ : chi square; $d f$ : degrees of freedom; TLI: Tucker-Lewis Index; CFI: Confirmatory Fit Index; RMSEA: root mean square error of approximation; MES: Motivation and Engagement Scale.

for the First Generation Australian students. In addition, across the three groups, latent factor correlations range from .92 (self-belief with value of school for the Aboriginal students) to -.72 (value of school with disengagement for the Aboriginal students). See Appendix 1.1-1.3 for a complete listing of factor loadings and correlations.

Factorial invariance testing models allowed judgements of confidence as to whether the structure and meaning of the MES and the Cultural Identity measure was equivalent across the three broad cultural groups. Table 2 provides the results for these invariance models. From Table 2, Models 2 to 4 all met the minimal and desirable invariance assumptions as per the criteria set by Cheung and Rensvold (2002) and Marsh, Tracey, and Craven (2006). The CFI varied less than .01 when compared to the free model, and there was also overlap in the $90 \%$ confidence interval of the RMSEA. 
Key finding for Aim (a): Psychometric validity

For the first aim of this investigation, the MES (Martin, 2003) and cultural identity measure (Cameron, 2004) was found to hold acceptable to strong psychometric properties for each of the three broad cultural groups. In addition, the factorial invariance testing revealed confidence that the implied structure and meaning of the measures may be consistent across the three broad culture groups. This is a positive finding as too often quantitative measures have been found to misrepresent the direct experiences of Aboriginal and Torres Strait Islander peoples in research (Nakata, 2007).

\section{Aim (b) Mean differences}

Table 3 offers the factor means for the motivation, identity and future aspiration variables and the beta paths for the difference testing between groups. The first group comparison model (Aboriginal and non-Aboriginal Australian) revealed acceptable goodness of fit indices $\left(\chi^{2}=3980.10, d f=1337, \mathrm{CFI}=.93, \mathrm{RMSEA}=.04\right)$ and a wide range of significant differences between the two groups. Across all the aspiration variables (with the exception of 'university aspiration') the non-Aboriginal Australian students held significantly higher mean scores. This was also the case for all the adaptive motivation measures with the exception of academic planning. Although the Aboriginal students held a significantly higher sense of cultural identity, they were also significantly higher on the impeding (e.g., anxiety) and maladaptive motivation dimensions.

A similar pattern of results was evident for the Aboriginal and First Generation Australian group comparison $\left(\chi^{2}=2938.09, d f=1337, \quad\right.$ CFI $=.91, \quad$ RMSEA $\left.=.04\right)$. The First Generation students held significantly higher means on all aspirations (except 'contribute to society') and adaptive motivational measures; the Aboriginal students held significantly higher impeding (with the exception of anxiety) and maladaptive motivational dimensions. For the non-Aboriginal and First Generation group comparison $\left(\chi^{2}=3902.83\right.$, $d f=1337, \mathrm{CFI}=.93$, RMSEA $=.04)$, only three significant differences were identified across all measures, with the First Generation students showing higher university aspirations, higher levels of anxiety and a stronger sense of cultural identity.

Key Finding (b): Mean differences

Whilst all student groups reported a strong sense of adaptive motivations and positive future aspirational outcomes, the mean difference testing identified a number of significant differences between the broad cultural groups. Probably the most consistent theme to emerge was that, with the exception of their sense of cultural identity, the Aboriginal students' consistently held lower future aspirations (e.g., raise a family, go to university) and adaptive motivational tendencies (e.g., self-belief, study management) than the non-Aboriginal and First Generation student groups. In addition, they showed higher levels of impeding (e.g., uncertain control) and maladaptive (e.g., disengagement) motivational tendencies. These findings stand in contrast to previous motivational research (Mclnerney, 20 I2; Mooney et al., 2016) that suggest that there are more similarities than differences between Aboriginal and nonAboriginal students with regard to their motivation at school. [AQ2] 


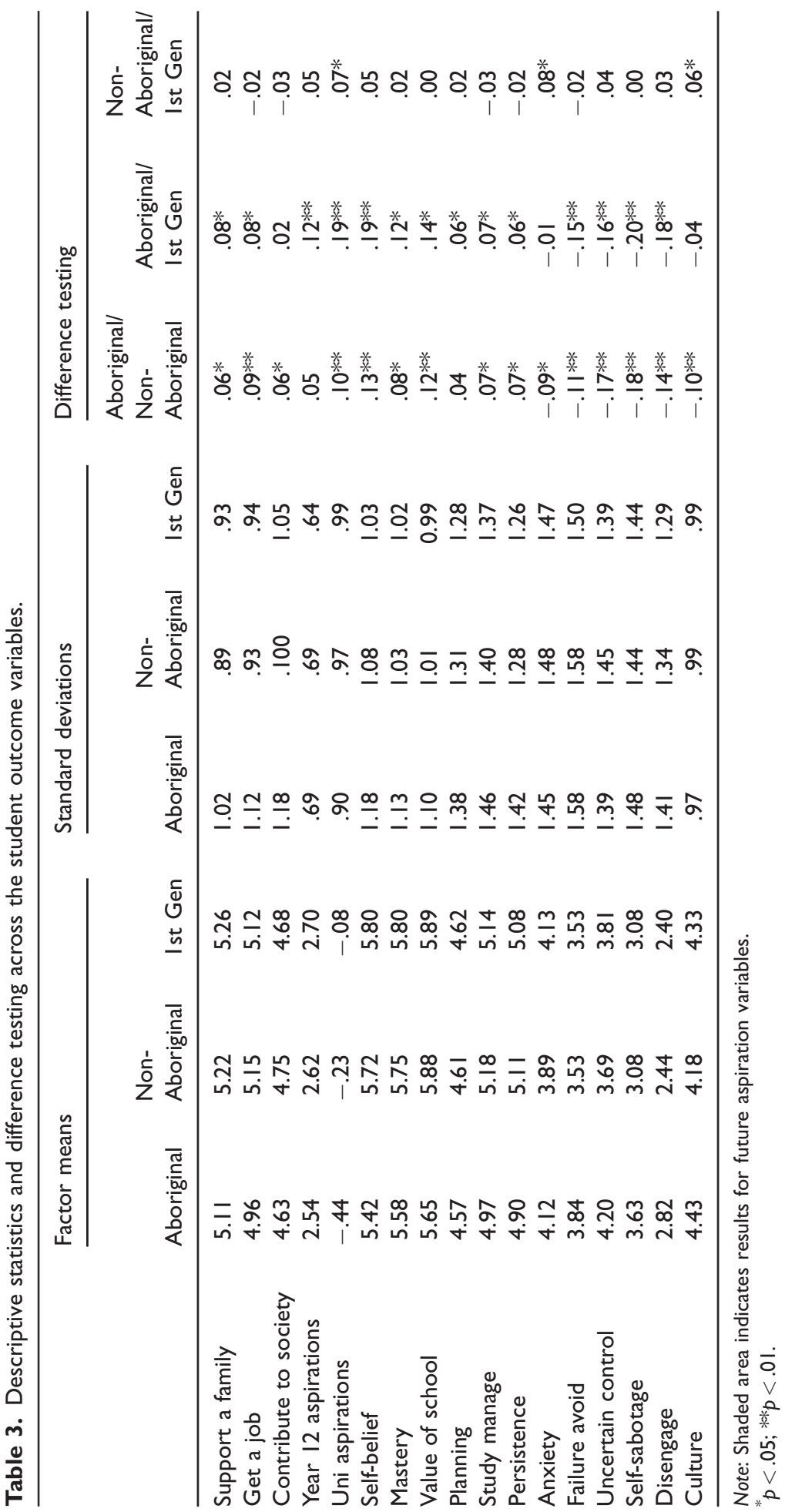




\section{Aim (c) Background variables and cultural identity predicting motivation and future aspirations}

Table 4 provides the results that are pertinent to Aim (c). Firstly for gender, of the 48 possible paths into motivation and future aspirations, only nine reached significance. For the Aboriginal students, males were significantly more likely to commit to self-sabotaging behaviours $(\beta=-.13, p<.05)$, and females were significantly more likely to aspire to go to university $(\beta=.14, p<.05)$. For the non-Aboriginal students, males were more likely to aspire to get a job $(\beta=-.11, p<.05)$, whereas females were significantly more likely to report higher levels of mastery $(\beta=.10, p<.05)$, commit to study management $(\beta=.07$, $p<.05)$, aspire to finish year $12(\beta=.14, p<.05)$ and go to university $(\beta=.18, p<.05)$, yet also displayed higher levels of anxiety $(\beta=.12, p<.001)$. Female First Generation students also displayed higher levels of anxiety $(\beta=.25, p<.001)$.

For grade-level, a consistent pattern of significant findings emerged for the adaptive motivational factors across all cultural groups. That is, of the 18 possible paths into the adaptive motivational factors, 15 were significant whereby later grade-level students showed lower adaptive motivational tendencies. The strongest predictor for the Aboriginal students was study management $(\beta=-.16, p<.05)$, yet persistence was the strongest for the nonAboriginal students $(\beta=-.23, p<.001)$, and planning $(\beta=-.28, p<.001)$ was the strongest for the First Generation students.

For the impeding and maladaptive motivational factors, no significant associations were found with regard to the predictive power of grade-level for the Aboriginal students, yet later grade-levels were associated with significantly higher levels of anxiety $(\beta=.13, p<.001)$ for the non-Aboriginal students, and self-sabotage $(\beta=.08, p<.05$ and $\beta=.13, p<.05)$, and disengagement $(\beta=.16, p<.001$ and $\beta=.18, p<.001)$ for the nonAboriginal and First Generation students, respectively. In addition, later grade nonAboriginal students were less likely to commit to the failure avoidance motivational factor $(\beta=-.08, p<.05)$.

Only three of the 15 possible paths into future aspirations were predicted by grade, whereby later grades were less likely to aspire to contribute to society for the nonAboriginal and First Generation students $(\beta=-.11, p<.05$ and $\beta=-.10, p<.05$ respectively) and, for the non-Aboriginal students only, finish Year $12(\beta=-.10, p<.05)$.

For parental university experience, only two significant paths were found (out of a possible 33) into the motivation factors, yet four (out of 15) were found for the future aspirations. That is, the non-Aboriginal students who had a parent attend university showed lower levels of uncertain control $(\beta=-.12, p<.001)$, and First Generation students who had a parent attend university showed higher levels of value of school $(\beta=.12, p<.05)$. Parental experience at university saw increased university aspirations for the Aboriginal, nonAboriginal, and First Generation student groups $(\beta=.19, p<.001, \beta=.17, p<.001$, and $\beta=.15, p<.001$ respectively), and increased aspirations to contribute to society $(\beta=.07$, $p<.05$ ) for the First Generation students.

For having a parent work full time, only seven of 48 paths were significant. The Aboriginal students who had a parent working full time showed lower levels of study management $(\beta=-.14, p<.05)$, whereas having a parent working full time showed lower levels of anxiety for the non-Aboriginal $(\beta=-.08, p<.05)$ and First Generation students $(\beta=-.18, p<.05)$, and lower levels of uncertain control $(\beta=-.13, p<.05)$ and selfsabotage $(\beta=-.13, p<.05)$ for the First Generation students. For the First Generation 
students, a parent working full-time saw increased aspirations to support a family $(\beta=.15$, $p<.05)$ and to go to university $(\beta=.16, p<.001)$.

Of the background variables, HER was the strongest independent predictor of the motivation factors and future aspirations, with 38 of the 48 paths reaching significance. For the Aboriginal students, 12 of the 16 paths emanating from HER were significant, with the strongest path being found for lowered levels of disengagement $(\beta=-.25, p<.001)$. For the non-Aboriginal students, 15 of the 16 paths were significant, with the strongest path from HER being found with higher levels of self-belief $(\beta=.24, p<.001)$. For the First Generation students, 11 of the 16 paths from HER were significant, with the strongest path being found with lowered levels of self-sabotage $(\beta=-.24, p<.001)$. It should be noted that across all groups, all the significant paths were in the direction of better outcomes (e.g., higher self-belief, lower levels of disengagement).

Finally, Table 4 reveals a range of moderately strong independent predictive paths emanating from the stronger sense of cultural identity for all student groups, particularly for higher levels of adaptive motivation. Overall, 36 of the possible 46 predictive paths into motivation and future aspirations reached significance, with the strongest significant path emerging for higher levels of mastery $(\beta=.48, p<.001)$ for the Aboriginal students. Identity also held the strongest predictive path over mastery for the non-Aboriginal students $(\beta=.40, p<.001)$ and for the First Generation students $(\beta=.46, p<.001)$. Overall, the results of the SEM path analysis suggest that over-and-above the predictive power of the background variables, a stronger sense of cultural identity seems to be the most powerful predictor of motivation (particularly the adaptive factors) and the future aspirational outcomes for all three cultural groups.

Key Finding (c): Predicting motivation and future aspirations

Arguably the most powerful finding to emerge from this study was that a positive sense of cultural identity was the strongest predictor of many of the motivational and future aspirational outcomes (over-and-above the influence of the background variables like home educational resources, a parent working full-time and having a history of studying at university) for all student groups. This suggests that researchers, teachers and policy makers should recognise that a student's sense of cultural identity could be intrinsically, and potently, associated with a stronger sense of motivation and engagement at school, particularly for Aboriginal students (Munns, et al., 2008; Preston \& Claypool, 20I3).

\section{Aim (d) Associations between motivation and future outcome variables}

Table 5 revealed the residual correlations (that is, once the explained variance of the background variables and culture have been factored out) between the motivation factors and the outcomes variables. From this table, it can be noted that a wide range of moderatelystrong and significant associations emerged for all cultural groups. In short, the strongest association for supporting a family was higher levels of planning for the Aboriginal students $(r=.27, p<.001)$, self-belief for the non-Aboriginal students $(r=.31, p<.001)$, and lower levels of disengagement for the First Generation students $(r=.23, p<.001)$. For getting a job, the strongest associations were self-belief for the Aboriginal students $(r=.29, p<.001)$, persistence for the non-Aboriginal students $(r=.33, p<.001)$, and self-belief for the First Generation students $(r=.33, p<.001)$. For contributing to society, the strongest 


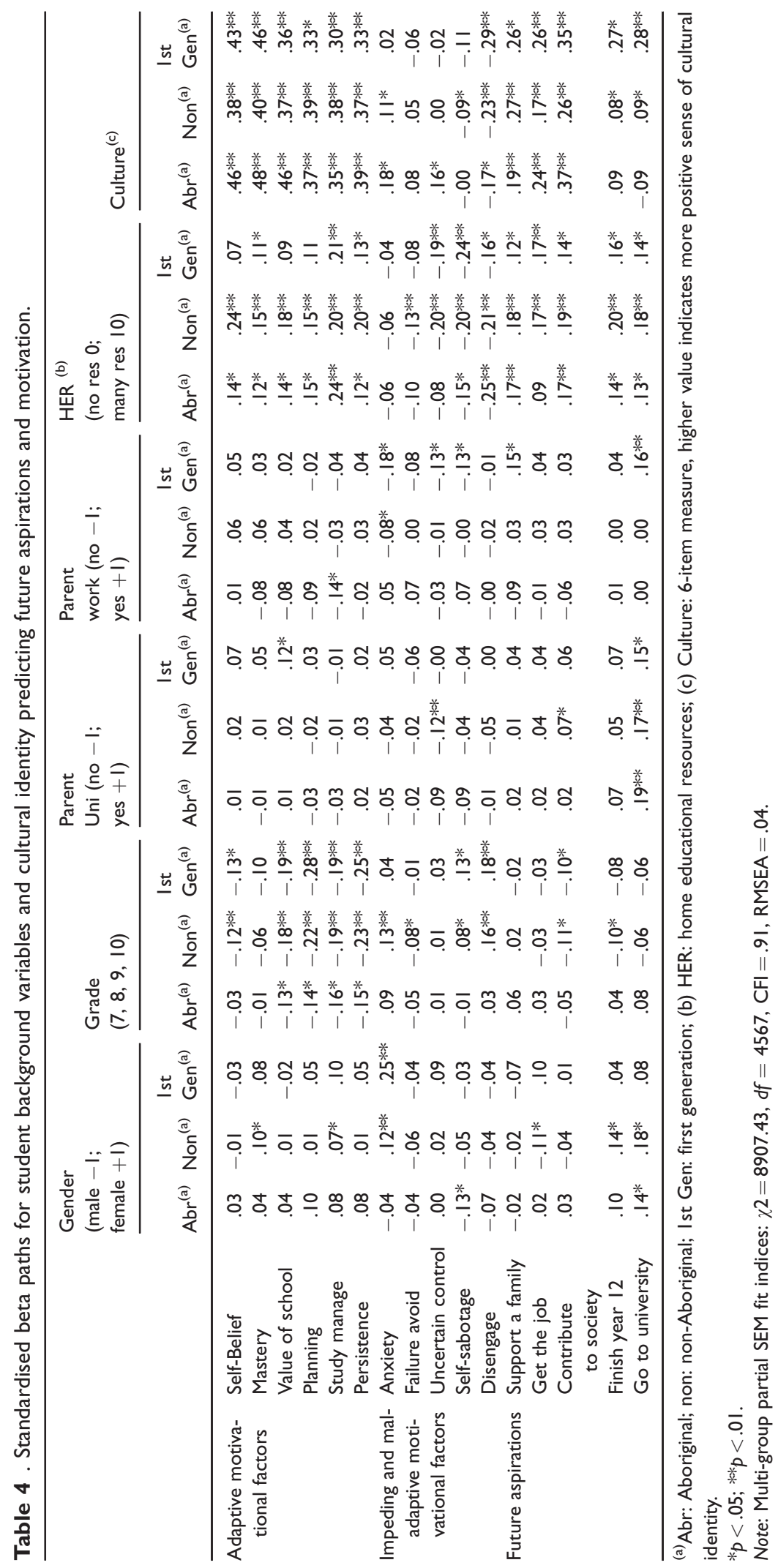




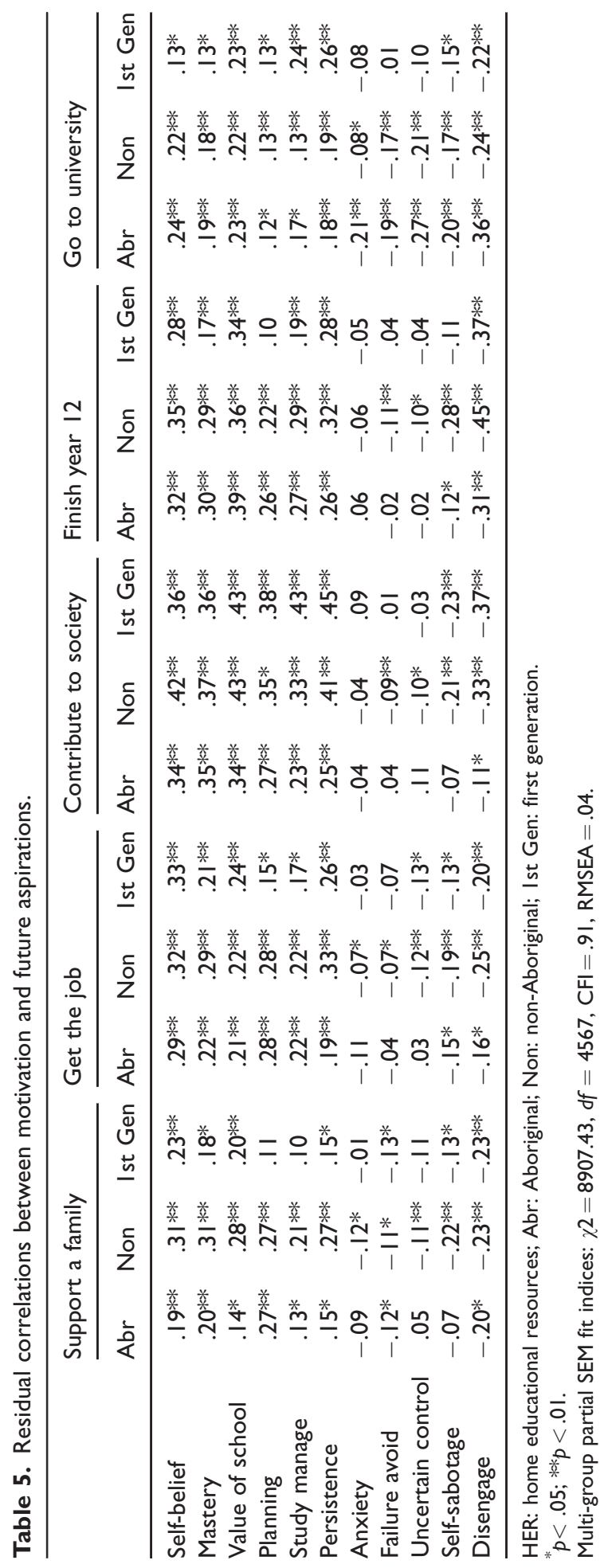


associations were mastery $(r=.35, p<.001)$ for the Aboriginal students, value of school for the non-Aboriginal students $(r=.43, p<.001)$ and persistence for the First Generation $(r=.45, p<.001)$ students. For finishing Year 12, the strongest association could be found in higher levels of value of school for the Aboriginal students $(r=.39, p<.001)$, and lower levels of disengagement for the non-Aboriginal students $(r=-.45, p<.001)$ and First Generation students $(r=-.37, p<.001)$. Finally, for aspiring to go to university, the strongest associations were found with lower levels of disengagement for the Aboriginal $(r=-.36, p<.001)$ and non-Aboriginal $(r=-.24, p<.001)$ students, and higher levels of persistence for the First Generation $(r=.26, p<.001)$ students. Overall, the results suggest that whilst cultural identity and HER seem relatively consistent in their independent predictive power over stronger aspirational outcomes for all student groups, the residual correlations with the MES suggest that a diversity of motivational factors may still be closely linked to student aspirations for the future.

Key Finding (d): Residual associations with motivation and future aspirations

Although cultural identity and a number of background variables held a range of significant associations with the future aspirational outcomes for the Aboriginal, non-Aboriginal and First Generation students, over-and-above these effects a diversity of motivational factors were still strongly associated with these outcomes. This finding, in part, suggests that motivation and identity may be linked, as both may be drivers of more positive futures for Aboriginal, non-Aboriginal and First Generation students. The implications of this finding are important when considering a range of theoretical perspectives that have carefully considered bi-epistemic approaches to both education for First Nations students (Battiste, 2002; Harris, 1990; Marika, Ngurruwutthun, \& White, 1992) and research methodologies seeking to prioritise more strongly Indigenous epistemologies (Nakata, 2007; Page, Trudgett, \& BodkinAndrews, 2016; Walter \& Andersen, 2013). That is, rather than placing Indigenous and Western epistemologies as confrontational constructs in learning, teaching and research - and ultimately minoritorising, othering, and subjugating Indigenous knowledges into a larger Western frameworks - research and teaching practises should continually attempt to ensure that the cultures and identities of First Nations students are valued and reinforced within diverse educational contexts (Kickett-Tucker \& Coffin, 20II).

\section{Discussion}

\section{Reframing the numbers: Indigenous led research}

Positivist writing practices often reject the introduction of research literature within the results and discussion sections of research articles, as there is an expectation that authors have considered all research possibilities within the literature review. It is the position of the authors of this article that any commitment to Indigenous research methodological standpoints should take a more reflexive approach to discussing results, as Indigenous-specific interpretive and epistemic relevancies are too often inadequately engaged with by subjugating positivistic, and Western frameworks.

Bodkin-Andrews, Bodkin, Andrews, and Whittaker (2016) have noted that Indigenous storytelling and learning practices, within and between diverse Aboriginal clans and nations, act as an intrinsic method of continual knowledge exchange between peoples over thousands of generations (see also Archibald, 2008; Martin, 2008). As a result, storytelling becomes an ongoing process of mutual learning that was not frozen into one time point, or one 'research 
paper' or 'literature review'. For the majority of this article, despite Indigenous standpoints being centred, there has only been one story told within the measures and statistics presented, and that is a story emanating from Western epistemologies. It is critical though that we understand how the results presented in this article speak to, and possibly with, research emanating from Indigenous led research standpoints (Kovach, 2009; Martin, 2008; Muller, 2014; Nakata, 2007; Walter \& Andersen, 2013).

With this article identifying strong links between identity and motivation for Aboriginal and Torres Strait Islander students, it is necessary to cite the 'strong and smart' philosophy of Sarra (2011). Drawn from a combination of Sarra's own successful experiences as a school principal and the development of the Stronger Smarter Institute for Indigenous Leadership, Sarra highlights multiple teaching and learning strategies for promoting the educational engagement and success of Aboriginal and Torres Strait Islander students. Importantly, these strategies were centred on strengthening positive Indigenous student identities through embracing Indigenous leadership within both schools and the local communities, and setting high expectations. Many of the strategies centred on stronger community partnerships to facilitate positive advances to the ethos of the school (e.g., promoting solidarity, uniforms, school song, cleaning programmes); higher expectations for attendance, achievement, and student behaviour within the school (e.g., clear expectations, negotiation, encouragement); whole Aboriginal studies programmes that moved beyond descriptive deficits (e.g., collaborative learning); and mentoring initiatives within the school (e.g., Elders, Indigenous teachers, community representatives). The success of these and other initiatives to promote stronger Aboriginal identities led Sarra (2011) to conclude that:

Poor leadership, anchored by inaccurate and negative perceptions of being Aboriginal, steered [the] school into a disgusting situation in which positive Aboriginal identity was not recognised, and not believed in ... Schools that are led by individuals who have a positive and accurate understanding of Aboriginal perceptions of being Aboriginal ... and ensure they are guided by Aboriginal leadership, will challenge, nurture and embrace Aboriginal students who will undoubtedly become stronger and smarter (p. 169).

Berryman and Bishop (2013) highlight another strong initiative through Te Kotahitanga, a New Zealand school reform project (Bishop, Berryman, Tiakiwai, \& Richardson, 2003). After gathering the voices of Māori students and families, an overwhelming set of deficit discourses (e.g., low expectations, self-fulfilling prophecies) were identified within teacher practices and attitudes. From this research, the Te Kotahitanga Effective Teaching Profile was developed as a foundation for professional development programmes to challenge teachers to reject deficit practices and commit to culturally responsive pedagogy. Such professional development training involved, through engaging with Māori protocols (e.g., using Māori meeting places, engaging with Elders), introducing teachers to the need for the Te Kotahitanga framework and self-monitoring, feedback sessions from facilitators who observed teaching practices within the classroom, teacher meetings to reflect on progress and to share evidence of successful practices, and show coaching teachers in goal setting, lesson plans and classroom flexibility.

In evaluating the Te Kotahitanga programme, Berryman and Bishop (2013) highlighted that teachers moved from dominant homogenous teaching approaches (whole class instruction) to discursive discourses that emphasised greater responsiveness to students and varying 
contexts for learning. Critically, later interviews with Māori students identified more productive and caring relationships between students and teachers, and Māori student performances were substantially stronger when compared to a control school. In short, this programme may be argued to have aided teachers to have become more responsive to the diverse learning identities of Māori students.

The two examples we have just cited are a small fraction of the Aboriginal and Torres Strait Islander and First Nations research base that centres and strengthens Indigenous epistemologies and identities. This increasing wealth of Indigenous-led research further clarifies how the findings within this article may be operationalised within the teaching and learning environment to potentially maximise the positive links between Aboriginal and Torres Strait Islander identity and motivation.

\section{Limitations and conclusion}

Moving beyond standard 'cross-sectional', and 'self-report' limitations that weaken inferences of causality (Bowen \& Wiersema, 1999), one of the strongest concerns within this investigation is the broad grouping of students within Aboriginal, non-Aboriginal, and First Generation groups (Walter \& Andersen, 2013). For example, Aboriginal Australian students are not part of a homogenous cultural group, but are a diverse multicultural group of peoples with differing language, histories, values and traditions (Trudgett \& Page, 2014; Walter \& Andersen, 2013). This limitation becomes most evident when attempting to apply meaning to the broad cultural identity measure, as there is an increasing base of Aboriginal and Torres Strait Islander research emerging to suggest that the cultural identities of Aboriginal youth are complex and multi-faceted constructs that move well beyond simplistic feel-good measures (e.g., I'm glad to be of my culture Cameron, 2004), and may differ substantially in nature to non-Indigenous students (Kickett-Tucker, 2009). It must be recognised then that the statistics within this article have failed to both move beyond the dichotomy of Indigeneity (and non-Aboriginal and First Generation) bias, and to accurately portray the complexities of Aboriginal identities. In further identifying how a positive cultural identity is associated with positive motivational tendencies (as opposed to competing approaches, e.g., Mooney et al., 2016) and future aspirations, engagement with the statistics portrayed in this article, and future research, must move beyond the pejorative and simplistic interpretations highlighted by Walter (2010).

Within empirical research contexts we have both emerging measures and databases, created and governed by Indigenous scholars and representatives, that more accurately portray complex representations of the lives and standpoints of Indigenous children, adults and families. For example, Kickett-Tucker et al. (2015) have developed and validated a racial identity and esteem measure based upon the voices of Aboriginal children, a measure which captures some of the diversities of what Aboriginal children know, and feel about, their cultural identity. With regards to secondary databases, the Longitudinal Study of Indigenous Children, a nation-wide study that began in 2008, has increasingly sought to engage with measures derived from Aboriginal and Torres Strait Islander standpoints (Walter et al., 2017). Engaging with this rich dataset, a recent article by Martin (2017) revealed that not only did Aboriginal parents/carers strongly value both their cultural knowledges and Indigeneity, but there was a diverse range of cultural knowledges that Aboriginal parents/carers felt needed to be passed onto their children (e.g., family history, 
respect, knowing Country). Both the research of Kickett-Tucker et al. (2015) and Martin (2017), and to a lesser extent this article, reveal how quantitative methodologies may speak to, and work with both qualitative methods and advances made from existing Indigenous Research Methodologies. For as Martin (2017, p. 96) suggests:

The strength of these results stand in contrast to deficit discourses that centre on all that is allegedly "wrong" with being Aboriginal and/or Torres Strait Islander and how it is the fault of our diverse cultures and values.

The implications to be drawn from the above limitations, future directions, and overarching findings of this article are that teachers and researchers could benefit from an increased understanding of what it means to be Aboriginal (and First Generation and non-Aboriginal Australian) among a diverse range of students, contexts and places. For example, teachers and educators should not limit their professional development activities to selected textbooks and 'cultural sensitivity' courses, but also seek to actively and respectfully (re)engage with Aboriginal and Torres Strait Islander families, Elders, communities and representative bodies to help ensure that the educational environment they provide is both academically motivating and culturally reinforcing for Aboriginal students (similar strategies may be applied to students from a variety of backgrounds). By respecting and engaging with both Aboriginal and Torres Strait Islander communities and Indigenous-centred research, volumes of academic literature reporting on the higher risk of Aboriginal student disengagement from school (Bodkin-Andrews et al., 2013) may gradually be replaced by more positive, and culturally meaningful frameworks (e.g., Berryman \& Bishop, 2013; KickettTucker \& Coffin, 2011; Preston \& Claypool, 2013; Sarra, 2011).

\section{Acknowledgements}

Further conceptual development with regards to Indigenous standpoints can also be attributed to the ARC special initiative, the National Indigenous Research and Knowledges Network, and the wisdom and generosity of the respected Aboriginal and Torres Strait Islander scholars within the network.

\section{Declaration of conflicting interests}

The author(s) declared no potential conflicts of interest with respect to the research, authorship, and/or publication of this article.

\section{Funding}

The author(s) disclosed receipt of the following financial support for the research, authorship, and/or publication of this article: this initial data gathering for this research was funded through the following Australian Research Council (ARC) grant: New Solutions For Maximising Secondary Indigenous Students? Full Potential: Identifying Causal Constructs That Enhance Indigenous Students' Aspirations and Educational Outcomes. ARC Linkage Project for APAI and ARC Discovery Grant, 2004-2007 (\$37,924).

\section{References}

Abramson, L., Seligman, Y., \& Teasdale, M. (1978). Learned helplessness in humans: Critique and reformulation. Abnormal Psychology, 87, 49-74. 
Andersen, C. (2016). The colonialism of Canada's Métis health population dynamics: Caught between bad data and no data at all. Journal of Population Research, 33(1), 67-82.

Archibald, J. A. (2008). Indigenous storywork: Educating the heart, mind, body, and spirit. Vancouver/ Toronto: BC press.

Bandura, A. (1997). Self-efficacy: The exercise of control. New York, NY: Freeman \& Co.

Battiste, M. (2002). Indigenous knowledge and pedagogy in First Nations education: A literature review with recommendations. Ottawa: Apamuwek Institute.

Beck, A. T. (1996). Beyond belief: A theory of modes, personality, and psychopathology. In P. M. Salkovskis (Ed.), Frontiers of cognitive therapy (pp. 1-25). New York, NY: Guilford.

Berryman, M., \& Bishop, R. (2013). Discursive repositioning in the Te Kotahitanga: Supporting teachers to improve the Educational experiences of Māori students in New Zealand. In R. Craven, G. Bodkin-Andrews \& J. Mooney (Eds), Indigenous peoples: A volume in international advances in education: Global initiatives for equity and social justice (pp. 233-254). Charlotte, NC: Information Age Publishing Inc.

Bishop, R., Berryman, M., Tiakiwai, S., \& Richardson, C. (2003). Te Kotahitanga: The experiences of year 9 and 10 Maori students in mainstream classrooms. Wellington: Ministry of Education.

Bodkin-Andrews, G. H., Craven, R. G., Parker, P., Kaur, G., \&Yeung, A. S. (2013). Motivational cognitions and behaviours for metropolitan Aboriginal and non-Aboriginal Australian students: Assessing the relations between motivation and school engagement. In G. Liem \& A. Bernardo (Eds), Advancing cross cultural perspectives on educational psychology (pp. 295-316). Information Age Publishing. [AQ3]

Bodkin-Andrews, G., \& Carlson, B. (2016). The legacy of racism and Indigenous Australian identity within education. Race Ethnicity and Education, 19(4), 784-807.

Bodkin-Andrews, G., Bodkin, F., Andrews, G., \& Whittaker, A. (2016). Mudjil 'dya' djurali Dabuwa' wurrata [how the white waratah became red]: D'harawal storytelling and Welcome to Country. AlterNative: An International Journal of Indigenous Peoples, 12(5), 480.

Bowen, H. P., \& Wiersema, M. F. (1999). Matching method to paradigm in strategy research: Limitations of cross-sectional analysis and some methodological alternatives. Strategic Management Journal, 20(7), 625-636.

Byrne, B. M (2012). Structural equation modelling with Mplus: Basic concepts, applications, and programming. New York, NY: Routledge.

Cameron, J. E. (2004). A three-factor model of social identity. Self and Identity, 3, 239-262.

Cheung, G. W., \& Rensvold, R. B. (2002). Evaluating goodness-of-fit indexes for testing measurement invariance. Structural Equation Modelling, 9, 233-255.

Covington, M. V. (2000). Goal theory, motivation and school achievement: An integrative review. Annual Review of Psychology, 51, 171-200.

Craven, R. G., Tucker, A., Munns, G., Hinkley, J., Marsh, H. W., \& Simpson, K. (2005). Indigenous students' aspirations: Dreams, perceptions and realities. DEST. Canberra: Commonwealth of Australia.

De Bortoli, L., \& Thomson, S. (2010). Contextual factors that influence the achievement of Australia's Indigenous students: Results from PISA 2000-2006. OECD Programme for International Student Assessment (PISA).

Ford, M. (2013). Achievement gaps in Australia: What NAPLAN reveals about education inequality in Australia. Race Ethnicity and Education, 16(1), 80-102.

Harris, S. (1990). Two-way Aboriginal schooling: Education and cultural survival. Canberra: Aboriginal Studies Press.

Harrison, N., \& Greenfield, M. (2011). Relationship to place: Positioning Aboriginal knowledge and perspectives in classroom pedagogies. Critical Studies in Education, 52(1), 65-76.

Hughes, H., \& Hughes, M. (2012). Poor education is letting Indigenous children down. Ideas for a better Australia: Centre for Independent Studies. Retrieved from https://www.cis.org.au/commen tary/articles/poor-education-is-letting-indigenous-children-down/ 
Kickett-Tucker, C. S. (2009). Moorn (Black)? Djardak (White)? How come I don't fit in Mum?: Exploring the racial identity of Australian Aboriginal children and youth. Health Sociology Review, 18(1), 119-136.

Kickett-Tucker, C. S., \& Coffin, J. (2011). Aboriginal self-concept and racial identity: Practical solutions for teachers. In N. Purdie, G. Milgate \& H. R. Bell (Eds), Two way teaching and learning (pp. 155-172). Melbourne: Australian Council for Educational Research.

Kickett-Tucker, C. S., Christensen, D., Lawrence, D., Zubrick, S. R., Johnson, D. J., \& Stanley, F. (2015). Development and validation of the Australian Aboriginal racial identity and self-esteem survey for 8-12 year old children (IRISE_C). International journal for equity in health, 14(1), 103.

Kovach, M. (2009). Indigenous methodologies: Characteristics, conversations, and contexts. Toronto: University of Toronto Press.

Kukutai, T., \& Taylor, J. (Eds). (2016). Indigenous data sovereignty: Toward an agenda (Vol. 38). ANU Press. Retrieved from https://press.anu.edu.au/publications/series/centre-aboriginal-economicpolicy-research-caepr/indigenous-data-sovereignty

Kukutai, T., \& Walter, M. (2015). Recognition and indigenizing official statistics: Reflections from Aotearoa New Zealand and Australia. Statistical Journal of the IAOS, 31(2), 317-326.

Liem, G. A. D., \& Martin, A. J. (2011). The Motivation and Engagement Scale: Theoretical framework, psychometric properties, and applied yields. Australian Psychologist, 47(1), 3-13.

Lovett, R. (2016). Aboriginal and Torres Strait Islander community wellbeing: Identified needs for statistical capacity. In T. Kukutai \& J. Taylor (Eds), Indigenous data sovereignty: toward an agenda (pp. 213). Canberra: Australian National University Press.

Magson, N. R., Bodkin-Andrews, G. H., Craven, R. G., Nelson, G. F., \& Yeung, A. S. (2013). Questioning new directions in understanding student motivation: An investigation into the domain specificity of motivational goals. The Australian Educational and Developmental Psychologist, 30(2), 171-190.

Marika, R., Ngurruwutthun, D., \& White, L. (1992). Always together, yakagäna: Participatory research at Yirrkala as part of the development of a Yolngu education. Convergence, 25(1), 23.

Marsh, H. W., Tracey, D. K., \& Craven, R. G. (2006). Multidimensional self-concept structure for preadolescents with mild intellectual disabilities: A hybrid multigroup-MIMC approach to factorial invariance and latent mean differences. Educational and Psychological Measurement, 66(5), 795-818.

Martin, A. J. (2006). A motivational psychology for the education of Indigenous Australian students. The Australian Journal of Indigenous Education, 35, 30-43.

Martin, A. J. (2009). Motivation and engagement across the academic life span: A developmental construct validity study of elementary school, high school, and university/college students. Educational and Psychological Measurement, 69(5), 794-824.

Martin, A. J., Ginns, P., Papworth, B., \& Nejad, H. (2013). The role of academic buoyancy in Aboriginal/Indigenous students' educational intentions: Sowing the early seeds of success for post-school education and training. In R. G. Craven \& J. Mooney (Eds), Seeding success in Indigenous Australian higher education (pp. 57-79) Bingley: Emerald Group Publishing Limited.

Martin, A. J., Yu, K., Papworth, B., Ginns, P., \& Collie, R. J. (2014). Motivation and engagement in the United States, Canada, United Kingdom, Australia, and China testing a multi-dimensional framework. Journal of Psychoeducational Assessment. Advance online publication. doi:10.1177/ 0734282914546287. [AQ4]

Martin, K. L. (2008). Please knock before you enter: Aboriginal regulation of outsiders and the implications for researchers. Australia: Post Pressed.

Martin, K. L. (2017). Culture and identity: LSIC parents' beliefs and values and raising young indigenous children in the twenty-first century. In M. Walter, K. Martin \& G. Bodkin-Andrews (Eds), Indigenous children growing up strong: A longitudinal study of Aboriginal and Torres Strait Islander Families (pp. 79-100). London: Palgrave MacMillan. 
McInerney, D. M., \& King, R. B. (2013). Harnessing the power of motivational factors for optimizing the educational success of remote indigenous students: A cross-cultural study. In R. G. Craven \& J. Mooney (Eds), Seeding success in indigenous Australian higher education (pp. 81-111) Bingley: Emerald Group Publishing Limited.

Mooney, J., Seaton, M., Kaur, G., Marsh, H. W., \& Yeung, A. S. (2016). Cultural perspectives on Indigenous and non-Indigenous Australian students' school motivation and engagement. Contemporary Educational Psychology, 47, 11-23.

Moreton-Robinson, A. (2009). Imagining the good indigenous citizen: Race war and the pathology of patriarchal white sovereignty. Cultural Studies Review, 15(2), 61-79.

Moreton-Robinson, A., \& Walter, M. (2009). Indigenous methodologies in social research. In M. Walter (Ed.), Social research methods (pp. 1-18). Melbourne: Oxford University Press.

Muller, L. (2014). A theory for Indigenous Australian health and human service work. Allen \& Unwin.

Munns, G., Martin, A. J., \& Craven, R. G. (2008). To free the spirit? Motivation and engagement of Indigenous students. Australian Journal of Indigenous Education, 37, 98-107.

Munns, G., O’Rourke, V., \& Bodkin-Andrews, G. (2013). Seeding success: Schools that work for Aboriginal students. Australian Journal of Indigenous Education 42(1), 1-11.

Muthén, B. O., \& Muthén, L. K. (2012). Mplus version 7: User's guide. Los Angeles, CA: Muthén \& Muthén.

Nakata, M. N. (2007). Disciplining the savages, savaging the disciplines. Canberra: Aboriginal Studies Press.

Nicholls, J. G. (1989). The competitive ethos and democratic education. Cambridge, MA: Harvard University Press.

Page, S., Trudgett, M., \& Bodkin-Andrews, G. (2016). Exploring an Indigenous graduate attribute project through a critical race theory lens. In M. Davis \& A. Goody (Eds), Research and development in higher education: The shape of higher education, 39 (pp. 258-267). Fremantle, Australia, 4-7 July 2016. Retrieved from http://herdsa.org.au/publications/conference-proceedings/research-anddevelopment-higher-education-shape-higher-24

Parker, P, D., Martin, A. J., Martinez, C., Marsh, H. W., \& Jackson, S, A. (2010). Stages of change in physical activity: A validation study in late adolescence. Health Education and Behavior, 37(3), 318329.

Pearson, N. (2011). Radical hope: Education and equality in Australia. Victoria: Black Inc.

Pintrich, P. R., \& Garcia, T. (1991). Student goal orientation and self-regulation in the college classroom. In M. Maehr \& P. R. Pintrich (Eds), Advances in motivation and achievement: Goals and selfregulatory processes (Vol. 7, pp. 371-402). Greenwich: JAI Press.

Preston, J. P., \& Claypool, T. R. (2013). Motivators of educational success: Perceptions of Grade 12 Aboriginal students. Canadian Journal of Education/Revue canadienne de l'éducation, 36(4), 257.

Sarra, C. (2011). Strong and smart - Towards a pedagogy for emancipation: education for first peoples. New York, NY: Routledge.

Shay, M., \& Wickes, J. (2017). Aboriginal identity in education settings: Privileging our stories as a way of deconstructing the past and re-imagining the future. The Australian Educational Researcher, 44(1), 107-122.

Smallwood, G. (2015). Indigenist critical realism: Human rights and first Australians' wellbeing. New York, NY: Routledge.

Smith, L. T. (2012). Decolonizing methodologies: Research and indigenous peoples. Zed books.

Steering Committee for the Review of Government Service Provision (SCRGSP). (2014). Overcoming indigenous disadvantage: Key indicators 2014, Productivity Commission, Canberra.

Trudgett, M., \& Page, S. (2014). When the Anths come marching in. The Australian Journal of Anthropology, 25(3), 388-390.

Urdan, T. C., \& Maehr, M. L. (1995). Beyond a two-goal theory of motivation and achievement: A case for social goals. Review of Education Research, 64(3), 213-243. 
Walter, M. (2010). The politics of the data: How the statistical indigene is constructed. International Journal of Critical Indigenous Studies, 3(2), 45-56.

Walter, M., \& Andersen, C. (2013). Indigenous statistics: A quantitative research methodology. California: Left Coast Press.

Walter, M., \& Butler, K. (2013). Teaching race to teach Indigeneity. Journal of Sociology, 49(4), 397-410.

Walter, M., Martin, K. L., \& Bodkin-Andrews, G. (2017). Indigenous children growing up strong: A longitudinal study of Aboriginal and Torres Strait Islander families. London: Palgrave MacMillan.

\section{Appendix I.I}

Table 6. MES-HS factor loadings and correlations from unrestrained multi-group CFA model for Aboriginal Australian students only.

\begin{tabular}{|c|c|c|c|c|c|c|c|c|c|c|c|c|}
\hline Item \# & $\begin{array}{l}\text { Self- } \\
\text { belief }\end{array}$ & Mastery & $\begin{array}{l}\text { Value of } \\
\text { school }\end{array}$ & Plan & $\begin{array}{l}\text { Study } \\
\text { manage }\end{array}$ & Persist & Anxiety & $\begin{array}{l}\text { Failure } \\
\text { avoid }\end{array}$ & $\begin{array}{l}\text { Uncertain } \\
\text { control }\end{array}$ & $\begin{array}{l}\text { Self- } \\
\text { sabotage }\end{array}$ & Disengage & Culture \\
\hline \multicolumn{13}{|l|}{ Factor loadings } \\
\hline I & $.67^{*}$ & $.7 I^{*}$ & $.63^{*}$ & $.65^{*}$ & $.67^{*}$ & $.7 I^{*}$ & $.70 *$ & $.78^{*}$ & $.64^{*}$ & $.49^{*}$ & $.57^{*}$ & $.57^{*}$ \\
\hline 2 & $.5 I^{*}$ & $.79 *$ & $.72^{*}$ & $.7 I^{*}$ & $.79 *$ & $.63^{*}$ & $.63 *$ & $.79 *$ & $.70^{*}$ & $.77^{*}$ & $.75^{*}$ & $.7 I^{*}$ \\
\hline 3 & $.7 I^{*}$ & $.70 *$ & $.63^{*}$ & $.85^{*}$ & $.84^{*}$ & $.53^{*}$ & $.53 *$ & $.58 *$ & $.57^{*}$ & $.74 *$ & $.62 *$ & $.72^{*}$ \\
\hline 4 & $.79 *$ & $.79 *$ & $.79 *$ & $.55^{*}$ & $.69 *$ & $.68^{*}$ & $.68 *$ & $.7 I^{*}$ & $.67^{*}$ & $.66^{*}$ & $.76 *$ & $.75^{*}$ \\
\hline 5 & - & - & - & - & - & - & - & - & - & - & - & $.54 *$ \\
\hline 6 & - & - & - & - & - & - & - & - & - & - & - & $.57^{*}$ \\
\hline \multicolumn{13}{|l|}{ Factor correlations } \\
\hline Self-belief & 1.00 & & & & & & & & & & & \\
\hline Mastery & $.86^{*}$ & 1.00 & & & & & & & & & & \\
\hline Value of school & $.92^{*}$ & $.89 *$ & 1.00 & & & & & & & & & \\
\hline Planning & $.76^{*}$ & $.63^{*}$ & $.67^{*}$ & 1.00 & & & & & & & & \\
\hline Study manage & $.80 *$ & $.70 *$ & $.74^{*}$ & $.84^{*}$ & 1.00 & & & & & & & \\
\hline Persistence & $.86^{*}$ & $.74^{*}$ & $.8 I^{*}$ & $.83^{*}$ & $.84 *$ & 1.00 & & & & & & \\
\hline Anxiety & $.16^{*}$ & $.16 *$ & $.24^{*}$ & $.17^{*}$ & $.19 *$ & $.28^{*}$ & 1.00 & & & & & \\
\hline Failure avoid & -.01 & .01 & -.05 & $.13^{*}$ & .10 & .11 & $.6 I^{*}$ & 1.00 & & & & \\
\hline Uncertain control & $.14^{*}$ & $.23 *$ & .10 & $.20^{*}$ & $.18^{*}$ & $.21^{*}$ & $.60^{*}$ & $.55^{*}$ & 1.00 & & & \\
\hline Self-sabotage & $-.27^{*}$ & $-.34^{*}$ & $-.38^{*}$ & $-.25^{*}$ & $-.26^{*}$ & $-.27^{*}$ & $.30 *$ & $.49 *$ & $.5 I^{*}$ & 1.00 & & \\
\hline Disengage & $-.60 *$ & $-.6 I^{*}$ & $-.72^{*}$ & $-.42^{*}$ & $-.46^{*}$ & $-.50 *$ & $.23^{*}$ & $.40 *$ & $.29 *$ & $.68 *$ & 1.00 & \\
\hline Culture & $.42 *$ & $.43^{*}$ & $.44^{*}$ & $.34 *$ & $.36^{*}$ & $.35^{*}$ & $.15^{*}$ & .08 & $.16 *$ & .01 & $-.17^{*}$ & 1.00 \\
\hline
\end{tabular}

CFA: confirmatory factor analysis; MES: Motivation and Engagement Scale.

* p significant at $<.05$.

\section{Appendix 1.2}

Table 7. MES-HS factor loadings and correlations for non-Aboriginal students only.

\begin{tabular}{|c|c|c|c|c|c|c|c|c|c|c|c|c|}
\hline Item \# & $\begin{array}{l}\text { Self- } \\
\text { belief }\end{array}$ & Mastery & $\begin{array}{l}\text { Value of } \\
\text { school }\end{array}$ & Plan & $\begin{array}{l}\text { Study } \\
\text { manage }\end{array}$ & Persist & Anxiety & $\begin{array}{l}\text { Failure } \\
\text { avoid }\end{array}$ & $\begin{array}{l}\text { Uncertain } \\
\text { control }\end{array}$ & $\begin{array}{l}\text { Self- } \\
\text { sabotage }\end{array}$ & Disengage & Culture \\
\hline \multicolumn{13}{|c|}{ Factor loadings } \\
\hline I & $.76^{*}$ & $.72 *$ & $.66^{*}$ & $.77^{*}$ & $.75^{*}$ & $.70^{*}$ & $.75^{*}$ & $.80 *$ & $.60^{*}$ & $.65^{*}$ & $.68^{*}$ & $.44^{*}$ \\
\hline 2 & $.62^{*}$ & $.77^{*}$ & $.79 *$ & $.7 I^{*}$ & $.75^{*}$ & $.74^{*}$ & $.70^{*}$ & $.85^{*}$ & $.72^{*}$ & $.75^{*}$ & $.78^{*}$ & $.67^{*}$ \\
\hline 3 & $.73^{*}$ & $.76^{*}$ & $.71 *$ & $.77^{*}$ & $.88^{*}$ & $.75^{*}$ & $.64 *$ & $.59 *$ & $.67 *$ & $.74^{*}$ & $.66^{*}$ & $.70 *$ \\
\hline 4 & $.82 *$ & $.79 *$ & $.8 I^{*}$ & $.48^{*}$ & $.79 *$ & $.82^{*}$ & $.68^{*}$ & $.74^{*}$ & $.73^{*}$ & $.72 *$ & $.8 I^{*}$ & $.79 *$ \\
\hline 5 & - & - & - & - & - & - & - & - & - & - & - & $.63^{*}$ \\
\hline 6 & - & - & - & - & - & - & - & - & - & - & - & $.64 *$ \\
\hline
\end{tabular}


Table 7. Continued

\begin{tabular}{|c|c|c|c|c|c|c|c|c|c|c|c|c|}
\hline Item \# & $\begin{array}{l}\text { Self- } \\
\text { belief }\end{array}$ & Mastery & $\begin{array}{l}\text { Value of } \\
\text { school }\end{array}$ & Plan & $\begin{array}{l}\text { Study } \\
\text { manage }\end{array}$ & Persist & Anxiety & $\begin{array}{l}\text { Failure } \\
\text { avoid }\end{array}$ & $\begin{array}{l}\text { Uncertain } \\
\text { control }\end{array}$ & $\begin{array}{l}\text { Self- } \\
\text { sabotage }\end{array}$ & Disengage & Culture \\
\hline \multicolumn{13}{|l|}{ Factor correlations } \\
\hline Self-belief & 1.00 & & & & & & & & & & & \\
\hline Mastery & $.86 *$ & 1.00 & & & & & & & & & & \\
\hline Value of school & $.84 *$ & $.82 *$ & 1.00 & & & & & & & & & \\
\hline Planning & $.74^{*}$ & $.74^{*}$ & $.73^{*}$ & 1.00 & & & & & & & & \\
\hline Study manage & $.73^{*}$ & $.72^{*}$ & $.73^{*}$ & $.85^{*}$ & 1.00 & & & & & & & \\
\hline Persistence & $.83 *$ & $.77^{*}$ & $.83^{*}$ & $.86^{*}$ & $.82 *$ & 1.00 & & & & & & \\
\hline Anxiety & -.03 & $.11 *$ & .07 & .05 & $.11 *$ & .06 & 1.00 & & & & & \\
\hline Failure avoid & -.06 & -.02 & -.05 & .00 & -.03 & -.04 & $.45^{*}$ & 1.00 & & & & \\
\hline Uncertain control & $-.19 *$ & $-.09 *$ & $-.13^{*}$ & -.06 & -.06 & $-.16^{*}$ & $.62^{*}$ & $.6 I^{*}$ & 1.00 & & & \\
\hline Self-sabotage & $-.40 *$ & $-.34 *$ & $-.36 *$ & $-.38 *$ & $-.37 *$ & $-.43^{*}$ & $.40^{*}$ & $.48 *$ & $.62^{*}$ & 1.00 & & \\
\hline Disengage & $-.68 *$ & $-.63^{*}$ & $-.7 I^{*}$ & $-.56^{*}$ & $-.59 *$ & $-.69 *$ & $.27^{*}$ & $.37^{*}$ & $.43^{*}$ & $.66^{*}$ & 1.00 & \\
\hline Culture & $.42 *$ & $.44^{*}$ & $.4 I^{*}$ & $.43 *$ & $.42 *$ & $.42 *$ & $.10^{*}$ & .03 & -.02 & $-.11 *$ & $-.26 *$ & 1.00 \\
\hline
\end{tabular}

MES: Motivation and Engagement Scale.

* $p$ significant at $<.05$.

\section{Appendix I.3}

Table 8. MES-HS factor loadings and correlations for First Generation students only.

\begin{tabular}{|c|c|c|c|c|c|c|c|c|c|c|c|c|}
\hline Item \# & $\begin{array}{l}\text { Self- } \\
\text { belief }\end{array}$ & Mastery & $\begin{array}{l}\text { Value of } \\
\text { school }\end{array}$ & Plan & $\begin{array}{l}\text { Study } \\
\text { manage }\end{array}$ & Persist & Anxiety & $\begin{array}{l}\text { Failure } \\
\text { avoid }\end{array}$ & $\begin{array}{l}\text { Uncertain } \\
\text { control }\end{array}$ & $\begin{array}{l}\text { Self- } \\
\text { sabotage }\end{array}$ & Disengage & Culture \\
\hline \multicolumn{13}{|l|}{ Factor loadings } \\
\hline I & $.79 *$ & $.75^{*}$ & $.60^{*}$ & $.75^{*}$ & $.75^{*}$ & $.7 I^{*}$ & $.77^{*}$ & $.75^{*}$ & $.54 *$ & $.65^{*}$ & $.55^{*}$ & $.46^{*}$ \\
\hline 2 & $.58^{*}$ & $.83^{*}$ & $.83^{*}$ & $.73^{*}$ & $.72 *$ & $.72^{*}$ & $.77^{*}$ & $.85^{*}$ & $.69 *$ & $.74^{*}$ & $.84^{*}$ & $.61 *$ \\
\hline 3 & $.73^{*}$ & $.74 *$ & $.70^{*}$ & $.79 *$ & $.84^{*}$ & $.79 *$ & $.58^{*}$ & $.50 *$ & $.66^{*}$ & $.76^{*}$ & $.69 *$ & $.74 *$ \\
\hline 4 & $.84 *$ & $.7 I^{*}$ & $.80^{*}$ & $.47^{*}$ & $.75^{*}$ & $.77^{*}$ & $.66^{*}$ & $.70 *$ & $.70 *$ & $.7 I^{*}$ & $.88^{*}$ & $.78^{*}$ \\
\hline 5 & - & - & - & - & - & - & - & - & - & - & - & $.67^{*}$ \\
\hline 6 & - & - & - & - & - & - & - & - & - & - & - & $.67^{*}$ \\
\hline \multicolumn{13}{|l|}{ Factor correlations } \\
\hline Self-belief & 1.00 & & & & & & & & & & & \\
\hline Mastery & $.84^{*}$ & 1.00 & & & & & & & & & & \\
\hline Value of school & $.90 *$ & $.84 *$ & 1.00 & & & & & & & & & \\
\hline Planning & $.67^{*}$ & $.67^{*}$ & $.70 *$ & 1.00 & & & & & & & & \\
\hline Study manage & $.63^{*}$ & $.68^{*}$ & $.68^{*}$ & $.86^{*}$ & 1.00 & & & & & & & \\
\hline Persistence & $.77^{*}$ & $.73^{*}$ & $.82^{*}$ & $.83^{*}$ & $.77^{*}$ & 1.00 & & & & & & \\
\hline Anxiety & $-.14^{*}$ & $.19 *$ & $.19 *$ & $.26^{*}$ & $.20^{*}$ & $.17^{*}$ & 1.00 & & & & & \\
\hline Failure avoid & .02 & -.03 & .01 & .06 & .02 & -.03 & $.42^{*}$ & 1.00 & & & & \\
\hline Uncertain control & -.08 & -.00 & -.02 & -.02 & -.03 & -.09 & $.57^{*}$ & $.55^{*}$ & 1.00 & & & \\
\hline Self-sabotage & $-.38^{*}$ & $-.40 *$ & $-.45^{*}$ & $-.48^{*}$ & $-.49 *$ & $-.53 *$ & .12 & $.54^{*}$ & $.40 *$ & 1.00 & & \\
\hline Disengage & $-.58^{*}$ & $-.59 *$ & $-.67^{*}$ & $-.5 I^{*}$ & $-.53^{*}$ & $-.63^{*}$ & .09 & $.23 *$ & $.26^{*}$ & $.54 *$ & 1.00 & \\
\hline Culture & $.48^{*}$ & $.52 *$ & $.40^{*}$ & $.37^{*}$ & $.36 *$ & $.39 *$ & .03 & -.07 & -.05 & $-.16 *$ & $-.34 *$ & 1.00 \\
\hline
\end{tabular}

MES: Motivation and Engagement Scale.

* $p$ significant at $<.05$. 